\title{
The relationship between vitamin $D$ status and depression in a tactical athlete population
}

\author{
Kelly A. Schaad ${ }^{1,2^{*}}$, Asma S. Bukhari ${ }^{1,2}$, Daniel I. Brooks ${ }^{3}$, Justin D. Kocher ${ }^{1,4}$ and Nicholas D. Barringer ${ }^{1,5}$
}

\begin{abstract}
Background: Stressors inherent to the military, such as combat exposure, separation from family, and strenuous training, collectively contribute to compromised psychological resilience and greatly impact military performance.

Methods: This retrospective review of records was conducted to determine whether vitamin D status was associated with diagnoses of depression and if diagnoses differed by geographic location.

Results: Depression (defined using diagnostic codes) was more prevalent in individuals who were diagnosed with vitamin D deficiency (20.4\%) than in individuals who were not (4.2\%). After adjustment, vitamin D deficient diagnoses remained significantly associated with depression diagnoses $(\mathrm{OR}=1.22 ; 95 \% \mathrm{Cl}, 1.11-1.33, p<0.001)$. Furthermore, vitamin $D$ deficient diagnoses were strongly associated with geographic latitude $\left(r^{2}=0.92, p=0.002\right)$.

Conclusion: These results suggest that service members stationed at installations located at northerly latitudes may be at increased risk for vitamin D deficiency. Furthermore, vitamin D deficient service members may be at higher risk for diagnosis of depression. As a number of military service members avoid reporting symptoms or seeking treatment, vitamin D status may be a useful screening tool to identify service members at risk for depression.
\end{abstract}

Keywords: Vitamin D, Depression, Service members, Latitude, Vitamin D deficiency

\section{Background}

Depression is a serious, yet common, mental disorder with symptoms that may have detrimental effects on daily activities of living, especially in the work environment [1]. Development of depression is multifactorial and risk factors may include family history, major life changes, trauma, stress, physical illness, or the use of certain medications [1]. In the United States military, the prevalence of depression is further influenced by unique stressors such as participation in armed conflicts and extended separation from family [2]. Previous studies estimate that major depression is prevalent among $12 \%$ of currently deployed military personnel, over $13 \%$ of previously deployed military personnel, and almost $6 \%$ of never deployed military personnel [3].

\footnotetext{
* Correspondence: kelly.a.schaad.mil@mail.mil

1 U.S. Baylor Military Graduate Program in Nutrition, 3630 Stanley Road, San Antonio, TX 78234, USA

${ }^{2}$ Nutrition Services Department, Walter Reed National Military Medical Center, 8901 Wisconsin Avenue, Bethesda, MD 20889, USA

Full list of author information is available at the end of the article
}

Although a vast number of prevention, reintegration, and resiliency programs exist to promote mental health among service members, a 2014 Institute of Medicine (IOM) report concluded that many of these programs and screening tools are based on insufficient evidence and lack validated measures [4]. It is also suggested that service members feel uncomfortable reporting depression and are reluctant to seek medical care due to the belief that treatment will negatively impact their career path $[5$, 6]. Improved screening methods for mental disorders would ensure that military units maintain sufficient performance levels to quickly deploy in support of a full range of military operations and would assist service members with reintegration following deployment.

Vitamin D status, particularly vitamin D deficiency, may be a risk factor for the development of psychological disorders such as depression [7]. Eyles et al. [7] concluded that although observational in nature, there is a growing body of epidemiological research to support the association between vitamin D status and psychiatric

(C) The Author(s). 2019 Open Access This article is distributed under the terms of the Creative Commons Attribution 4.0 International License (http://creativecommons.org/licenses/by/4.0/), which permits unrestricted use, distribution, and 
outcomes. One proposed mechanism suggests that a deficiency of vitamin D alters the release of certain neurotransmitters in the brain $[7,8]$. Although vitamin $\mathrm{D}$ is most commonly known for its role in calcium homeostasis and bone development, vitamin $\mathrm{D}$ receptors have been discovered in nearly all tissues in the body, indicating that vitamin $\mathrm{D}$ has additional physiological functions, including a neuroprotective role [9]. Vitamin D receptors expressed in neurotransmitter pathways can affect the synthesis of dopamine and serotonin, leading to a disruption in feelings of reward, motivation, pleasure, and drive $[8,9]$.

Vitamin D deficiency is common in the United States and is estimated to be prevalent among $35-41.5 \%$ of adults $[10-12]$. Few foods are naturally abundant in vitamin $D$ and synthesis of the vitamin occurs primarily after exposure of the skin to ultraviolet (UV) radiation from sunlight. Optimal exposure to UV radiation occurs closest to the equator and during summer months, and is further influenced by elevation, season, cloud cover, and the time of day $[13,14]$. Consequently, during winter months, vitamin $\mathrm{D}$ production is very low at latitudes above approximately $33^{\circ} \mathrm{N}$ or below $33^{\circ} \mathrm{S}$ [13]. Vitamin $\mathrm{D}$ deficiency is of interest within the military population, as Umhau et al. [15] and Funderburk et al. [16] reported that 30 and $21 \%$ of a sample of U.S. military service members were vitamin D deficient, respectively.

Previous studies assessing the relationship between vitamin $\mathrm{D}$ deficiency and depression show inconsistent results. In older adults, it is reported that lower vitamin D levels are associated with major depression, minor depression, and depressive symptoms $[17,18]$. Likewise, Lapid et al. [19] found that in an elderly population, those with severe vitamin $\mathrm{D}$ deficiency were twice as likely to have a diagnosis of depression. However, in populations with comorbid conditions, such as multiple sclerosis, there was a negative correlation between vitamin $\mathrm{D}$ status and depression [20]. Additional factors may impact the relationship between vitamin D and depression, as Pan et al. [21] and Nanri et al. [22] both demonstrated that season and geographic location can affect the relationship between vitamin D and depression.

Existing studies on the relationship between vitamin D and depression have been conducted primarily in elderly populations or in populations with comorbidities and may not be applicable to active duty military personnel. Current demographics describe the U.S military population as relatively young, active, and with a low prevalence of chronic disease [23, 24]. Therefore, the purpose of this study was to assess the relationship between vitamin D status and depression in active duty service members. Furthermore, this study aimed to determine if there was a relationship between vitamin D status, depression, and geographic location. We hypothesized that diagnoses of vitamin $\mathrm{D}$ deficiency would be associated with diagnoses of depression. In addition, we hypothesized that there would be a higher number of vitamin $\mathrm{D}$ deficient diagnoses and depression diagnoses at military treatment facilities (MTFs) located above $33^{\circ} \mathrm{N}$ latitude than at military treatment facilities located below $33^{\circ} \mathrm{N}$ latitude.

\section{Methods}

\section{Data source}

Data for this study were obtained from the Military Health System (MHS) Data Repository (MDR), which contains information from a comprehensive network of military healthcare clinics that serve over 9.5 million beneficiaries [25]. Specifically, data were retrieved from the direct care component of the MDR. These records are referred to as direct care because the services are provided at MTFs operated solely by the Department of Defense (DoD) [25]. The data system, known as the Management and Analysis and Reporting Tool (M2), was used to query the MDR for Comprehensive Ambulatory Provider Encounter Records (CAPERs), which contain outpatient records for all encounters occurring at MTFs. Examples of outpatient encounters include primary care, wellness, specialty care, and group appointments. The M2 database was queried only for approved data and the workstation used for accessing data met DoD security requirements. This study was approved by the Human Protections Administrator at the Army Medical Department Center and School and the Institutional Review Board at Walter Reed National Military Medical Center.

\section{Extracted data}

Study data were retrieved from the MHS for the years 2013 through 2015. Each record in the dataset contained: a pseudo identification number (an encrypted individual identifier that is comparable across datasets), the treatment facility name and identification, the common beneficiary category (confirmation that the individual was serving on active duty or active duty orders at the time of data retrieval), the specific beneficiary category (to separate Army Guard or Army Reserve on active duty orders from Regular Army status), gender (male or female), age group (four age categories: 18-24, 25-34, 35-44, and 45-64), sponsor rank group (the service members' pay grade grouped in a broader category: enlisted junior, enlisted senior, officer junior, and officer senior), encounters (a count of records), and diagnosis (a diagnostic code for either vitamin D deficiency or depression as the chief complaint or as any of the secondary diagnoses up to the 10 maximum allowable codes).

\section{Exposure and outcome variables}

The primary exposure variable, diagnosis of vitamin $\mathrm{D}$ deficiency, was defined as having at least one encounter 
with a primary or secondary Ninth Revision of the International Classification of Diseases, Clinical Modification (ICD-9-CM) code 268.9, Unspecified vitamin D deficiency [26]. The appearance of the diagnostic code for vitamin D deficiency in the record indicated that a clinical provider ordered a reliable laboratory assay to evaluate serum circulating levels of vitamin D prior to diagnosis. The Endocrine Society Clinical Practice Guidelines defines vitamin D deficiency as a 25-hydroxyvitamin D [25(OH)D] level of $<20 \mathrm{ng} / \mathrm{mL}(50 \mathrm{nmol} / \mathrm{L})$ and recommends testing for the serum circulating levels of $25(\mathrm{OH}) \mathrm{D}$ in order to evaluate vitamin D status [13]. Although the Endocrine Society guidelines are commonly used for the testing and diagnosing of vitamin D status, due to limitations of using ICD-9$\mathrm{CM}$ codes as the sole means to confirm diagnosis, this study was unable to verify if providers adhered to these methods.

The primary outcome variable, diagnosis of depression, was defined as having at least one encounter with either a primary or secondary diagnosis from the ICD-9-CM codes listed in Table 1 [26]. A diagnosis of depression is generally symptom-based for a specified period of time and determined using the diagnostic criteria outlined in the Diagnostic and Statistical Manual of Mental Disorders (DSM-V) [27]. The method for identifying diagnoses of depression by ICD-9-CM codes in this study is comparable to strategies used by previous studies $[28,29]$. Similarly to the methods used for determining a diagnosis of vitamin D deficiency, the use of ICD-9-CM codes, to confirm diagnosis of depression, does not differentiate whether medical providers diagnosed accurately or within the accepted guidelines.

\section{Study population}

Individuals serving on active duty in the United States Army during the study period, with records for selected MTFs, were included for review $(n=483,683)$. Outpatient records were obtained for six military treatment facilities at varying geographic locations (Watertown,

Table 1 Selected ICD-9-CM codes for depression and description

\begin{tabular}{ll}
$\begin{array}{l}\text { ICD-9-CM } \\
\text { Code }\end{array}$ & Description \\
\hline 296.22 & Major depressive affective disorder single episode \\
296.3 & $\begin{array}{l}\text { Major depressive affective disorder recurrent episode } \\
\text { unspecified degree }\end{array}$ \\
296.31 & Major depressive affective disorder recurrent \\
296.32 & $\begin{array}{l}\text { Major depressive affective disorder recurrent episode } \\
\text { moderate degree }\end{array}$ \\
296.33 & $\begin{array}{l}\text { Major depressive affective disorder recurrent episode } \\
\text { severe degree without psychotic behavior }\end{array}$ \\
311 & Unspecified episodic mood disorder \\
\hline
\end{tabular}

New York; Fairbanks, Alaska; Killeen, Texas; Tacoma, Washington; El Paso, Texas; and Fayetteville, North Carolina) in order to examine latitude as an independent variable (Fig. 1). Geographic location was a consideration in this study given that absorption of UV radiation, essential for vitamin D production, varies depending on degree of latitude. In order to capture personnel stationed at installations for a reasonable period of time, selection of MTFs on known training installations was avoided due to the transient nature of this population. Consequently, only MTFs located on installations without Initial Entry Training (IET) programs were included for review.

In order to associate demographic characteristics and medical outcomes without biasing the data, only one unique record was kept for each pseudo-identification number. Therefore, records with pseudo-identification numbers that appeared more than once $(168,052)$ were reduced so that only the pseudo-identification number associated with the largest number of encounters was retained $(n=71,506)$, as a duplication indicated that an individual had outpatient encounters at multiple MTFs or had a change in demographic data during the study period. For records with multiple demographic characteristics but no maximum number of encounters, the first appearance in the dataset was kept arbitrarily $(n=$ 6873). Records were eliminated to exclude individuals outside of the predetermined, 18-64 year old age parameter (99 total records excluded); to exclude military ranks other than junior enlisted, senior enlisted, junior officer, or senior officer (11,912 records excluded); and to exclude records without a listed gender (1 record excluded). Finally, individuals with $\geq 300$ encounters were considered outliers and excluded from the dataset (189 total records excluded). After removing duplicates, outliers, and records excluded for the reasons above, 381,818 unique records remained for subsequent data analysis.

\section{Statistical methods}

All demographic characteristics for this study were categorical and were described as a total number and frequency. A Chi-square test of independence was used to compare frequencies of vitamin D deficiency and depression between MTFs. The primary means of analysis was a binomial generalized linear model with a log link that was used to predict depression diagnosis. An initial model (Model 1) was created and included only vitamin D diagnosis; followed by a secondary model (Model 2) which included vitamin D diagnosis and a group of other covariates (MTF location, gender, age group, service type, career type, and career progression). Finally, a third model (Model 3) included these covariates as well as the number of associated encounters as a 


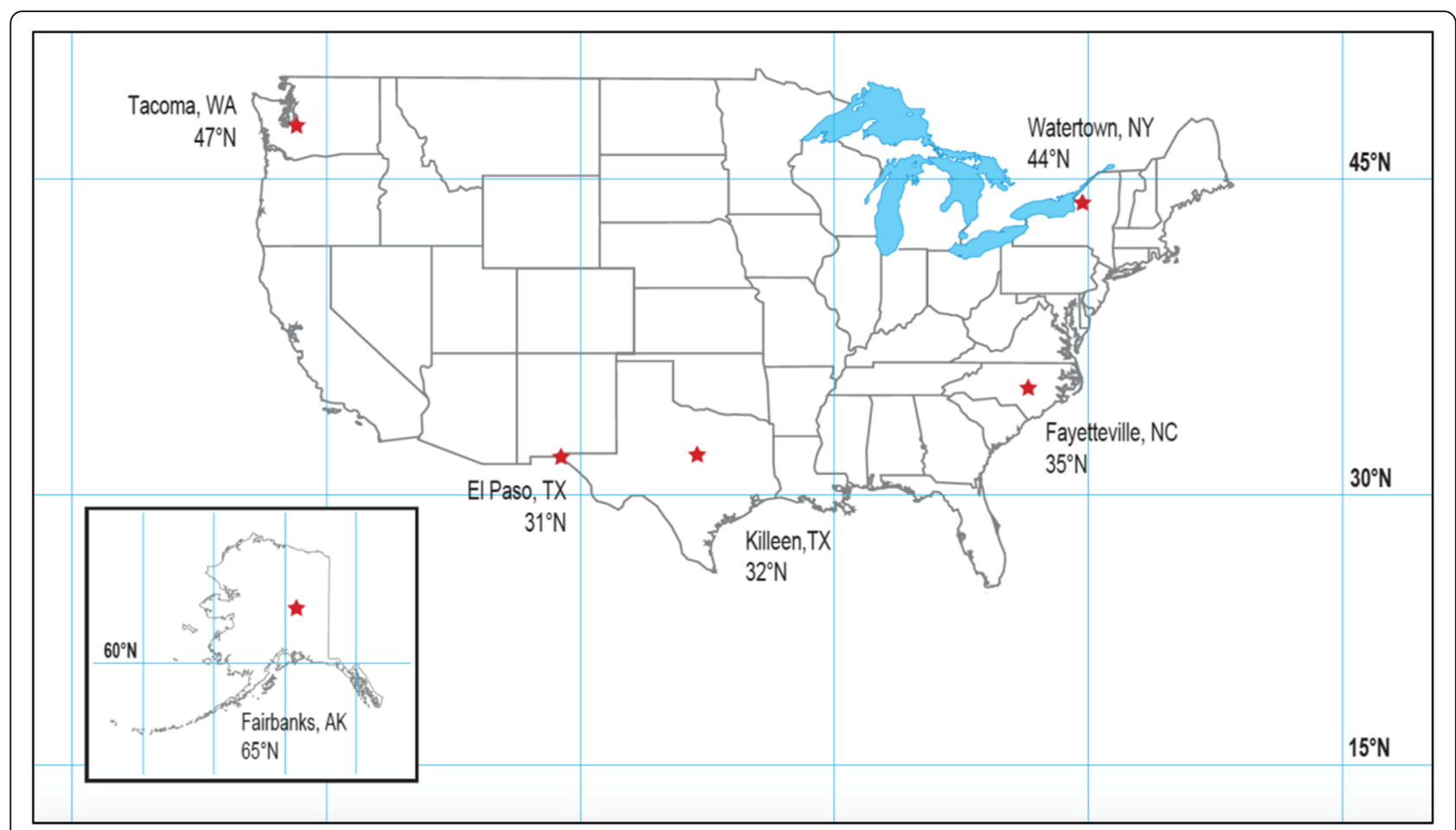

Fig. 1 Geographic locations and associated latitudes for military treatment facilities where outpatient records were retrieved between the years 2013 and 2015

continuous variable. In this model, encounters were log transformed to approximate normality. Significance in each model was evaluated using a Type 3 Likelihood Ratio test. Odds ratios (and 95\% confidence intervals) for individual parameters were extracted using exponentiated parameter estimates.

To examine the relationship between MTF latitude and vitamin $\mathrm{D}$ diagnosis, a separate model was built to predict vitamin D diagnosis (as in Model 3, above). From this model, the estimated rate of vitamin D deficiency at each MTF was calculated using least square means. These extracted rates were then correlated with the actual latitude of each MTF. Global alpha was set at $p<0.05$ for each analysis and statistical analysis was conducted using IBM SPSS Statistics version 24.0; SPSS Inc., Chicago, Illinois and R Statistical Software (R Foundation for Statistical Computing, Vienna, Austria).

\section{Results}

The demographic characteristics of the study sample, grouped by geographic location, are presented in Table 2 . Of the total sample, $80.8 \%$ were active duty Army, $86.2 \%$ were male, and $86.3 \%$ were enlisted. The greatest number of records were obtained from the MTF located in Killeen, $\mathrm{TX}$, whereas the fewest number of records were obtained from the MTF located in Fairbanks, AK. The largest age group was the 25-34 year old age group, followed by the $18-24$ year old age group, which made up 40 and $36.9 \%$ of the sample, respectively. In total, $40 \%$ of personnel were senior ranking, compared to $60 \%$ of personnel that were junior ranking.

Prevalence of vitamin D deficient diagnoses among this sample of active duty service members was $<1 \%$, while the prevalence of depression was $4.37 \%$. Diagnoses of depression were highest for the MTF located in Killeen, TX, followed by the MTF in Fairbanks, AK, and lowest for the MTF located in Watertown, NY. However, diagnoses of vitamin D deficiency were highest for the MTF located in Tacoma, WA, followed by the MTF for Fairbanks, AK, and lowest for the MTF located in Killeen TX. Raw frequencies and counts for each diagnosis, split by MTF location, are shown in Table 3.

Overall, depression was more prevalent in individuals who were diagnosed with vitamin D deficiency (20.4\%) than in individuals who were not (4.2\%). Table 4 shows the results of predicting depression diagnosis using three separate models. Model 1 demonstrates that, without including other covariates, diagnoses of vitamin D deficiency were significantly associated with diagnoses of depression $(\mathrm{OR}=5.84 ;$ 95\% CI, 5.41-6.33 $p<0.001)$. This relationship remained significant (Model 2) after adjustment for sociodemographic characteristics and location (gender, age, service type, career type, career progression, and MTF location $)(\mathrm{OR}=5.38$; 95\% CI, 4.95-5.88 $p<0.001)$.

In an additional adjusted model (Model 3 ), the number of patient encounters, as a covariate, was also included for 
Table 2 Demographic characteristics of active duty service members by military treatment facility location

\begin{tabular}{|c|c|c|c|c|c|c|c|c|c|c|c|c|c|c|}
\hline \multirow[t]{2}{*}{ MTF Location } & \multicolumn{2}{|c|}{ Fairbanks, AK } & \multicolumn{2}{|c|}{ Watertown, NY } & \multicolumn{2}{|c|}{ Tacoma, WA } & \multicolumn{2}{|c|}{ Fayetteville, NC } & \multicolumn{2}{|l|}{ El Paso, TX } & \multicolumn{2}{|l|}{ Killeen, TX } & \multirow{2}{*}{$\begin{array}{l}\text { Totals } \\
n=381,818\end{array}$} & \multirow[b]{2}{*}{$\%$} \\
\hline & $n=10,920$ & $\%$ & $n=31,130$ & $\%$ & $n=59,613$ & $\%$ & $n=88,826$ & $\%$ & $n=90,667$ & $\%$ & $n=100,662$ & $\%$ & & \\
\hline \multicolumn{15}{|l|}{ Characteristic } \\
\hline \multicolumn{15}{|l|}{ Service Type } \\
\hline Active Army & 10,534 & 96.5 & 29,810 & 95.8 & 55,147 & 92.5 & 82,591 & 93 & 55,015 & 60.7 & 75,312 & 74.8 & 308,409 & 80.8 \\
\hline Active Guard & 386 & 3.5 & 1320 & 4.2 & 4466 & 7.5 & 6235 & 7 & 33,652 & 39.3 & 25,350 & 25.2 & 73,409 & 19.2 \\
\hline \multicolumn{15}{|l|}{ Gender } \\
\hline Male & 9799 & 89.7 & 27,850 & 89.5 & 50,979 & 85.5 & 77,150 & 86.9 & 78,521 & 86.6 & 84,786 & 84.2 & 329,085 & 86.2 \\
\hline Female & 1121 & 10.3 & 3280 & 10.5 & 8634 & 14.5 & 11,676 & 10.3 & 12,146 & 13.4 & 15,876 & 15.8 & 52,733 & 13.8 \\
\hline \multicolumn{15}{|l|}{ Age Group, Years } \\
\hline $18-24$ & 5058 & 46.3 & 13,789 & 44.3 & 21,739 & 36.5 & 30,686 & 34.5 & 32,809 & 36.2 & 36,949 & 36.7 & 141,030 & 36.9 \\
\hline $25-34$ & 4243 & 38.9 & 11,762 & 37.8 & 24,689 & 41.4 & 37,917 & 42.7 & 34,431 & 38 & 39,504 & 39.2 & 152,546 & 40 \\
\hline $35-44$ & 1339 & 12.3 & 4479 & 14.4 & 10,103 & 16.9 & 15,325 & 17.3 & 16,338 & 18 & 17,606 & 14.5 & 65,190 & 17.1 \\
\hline $45-64$ & 280 & 2.6 & 1100 & 3.5 & 3082 & 5.2 & 4898 & 5.5 & 7089 & 7.8 & 6603 & 6.6 & 23,052 & 6 \\
\hline \multicolumn{15}{|l|}{ Career Type } \\
\hline Enlisted & 9846 & 90.2 & 27,504 & 88.4 & 51,312 & 86.1 & 75,154 & 84.6 & 77,752 & 85.8 & 87,890 & 87.3 & 329,458 & 86.3 \\
\hline Officer & 1074 & 9.8 & 3626 & 11.6 & 8301 & 13.9 & 13,672 & 15.4 & 12,915 & 14.2 & 12,772 & 12.7 & 52,360 & 13.7 \\
\hline \multicolumn{15}{|c|}{ Career Progression } \\
\hline Junior Rank & 7571 & 69.3 & 20,735 & 66.6 & 37,483 & 62.9 & 49,434 & 55.7 & 54,132 & 59.7 & 59,806 & 59.4 & 229,161 & 60 \\
\hline Senior Rank & 3349 & 30.7 & 10,395 & 33.4 & 22,130 & 37.1 & 39,392 & 44.3 & 36,535 & 40.3 & 40,856 & 40.6 & 152,657 & 40 \\
\hline
\end{tabular}

analysis. This variable, which represents the number of distinct medical encounters for each individual, was included after preliminary analysis indicated that it had a strong relationship with a diagnosis of both vitamin $\mathrm{D}$ deficiency and depression. Inclusion of the number of encounters as a covariate accounted for a large amount of the variance in depression diagnoses $(\mathrm{OR}=3.66$, CI, 3.59$3.72 p<0.001)$ and strongly attenuated the relationship between Vitamin D Deficiency and depression $(\mathrm{OR}=1.22$; 95\% CI, 1.11-1.33), however, this relationship remained significant $(p<0.001)$. Similarly, other covariates remained significant predictors for a diagnosis of depression, but with a reduced relationship.

Table 3 Vitamin D deficiency and depression diagnoses between the years 2013 and 2015 for active duty service members by military treatment facility location

\begin{tabular}{|c|c|c|c|c|c|}
\hline \multicolumn{2}{|l|}{ MTF Location } & \multicolumn{2}{|c|}{ Depression } & \multicolumn{2}{|c|}{ Vitamin D } \\
\hline & $n$ & Count & Frequency & Count & Frequency \\
\hline Watertown, NY & 31,130 & 1008 & $3.24 \%$ & 460 & $1.48 \%$ \\
\hline Fairbanks, AK & 10,920 & 474 & $4.34 \%$ & 215 & $1.97 \%$ \\
\hline Killeen, TX & 100,662 & 6537 & $6.49 \%$ & 310 & $0.31 \%$ \\
\hline Tacoma, WA & 59,613 & 2390 & $4.01 \%$ & 1363 & $2.29 \%$ \\
\hline El Paso, TX & 90,667 & 2988 & $3.30 \%$ & 410 & $0.45 \%$ \\
\hline Fayetteville, NC & 88,826 & 3291 & $3.70 \%$ & 972 & $1.09 \%$ \\
\hline Totals: & 381,818 & 16,688 & & 3730 & \\
\hline
\end{tabular}

Finally, an analysis of the raw vitamin D deficiency percentages and (log transformed) latitude revealed a significant linear relationship $\left(r^{2}=0.75, p=0.026\right)$. Rates of vitamin $\mathrm{D}$ deficiency were also modeled using a quasipoisson generalized linear model, using depression, gender, age group, service type, career type, career progression, and encounters as covariates. Least squared mean predictions for each MTF, using an average number of encounters [13] and regular active duty Army status, were extracted from that model, which demonstrated an even stronger relationship between vitamin D deficiency and log latitude (Fig. 2) $\left(r^{2}=0.92, p=0.002\right)$.

\section{Discussion}

This retrospective cross-sectional study describes significant associations between vitamin D deficiency, depression, and geographic location. Of the 381,818 records that were included for analysis, a total of 3730 records contained a diagnostic code for vitamin $\mathrm{D}$ deficiency. The overall prevalence of vitamin D deficiency $(<1 \%)$, found in this study, is notably lower than previous studies of military personnel; which report that vitamin $\mathrm{D}$ deficiency ranges between 16 and 30\% [15, 16]. The prevalence of vitamin D deficiency diagnoses were highest among males, the senior enlisted group, and the 25-34 year old age group. As this study only reviewed diagnoses, the actual number of service members who were examined for vitamin D status could not be determined. With this limitation, it is possible 
Table 4 Unadjusted and adjusted odds ratio and level of significance for analysis of the association between diagnosis of vitamin D deficiency and diagnosis of depression

\begin{tabular}{|c|c|c|c|c|c|c|c|c|c|}
\hline \multirow[t]{2}{*}{ Parameter } & \multicolumn{3}{|c|}{ Model $1^{a}$} & \multicolumn{3}{|c|}{ Model $2^{b}$} & \multicolumn{3}{|c|}{ Model $3^{c}$} \\
\hline & $\overline{\mathrm{OR}}$ & $p$ value & $\mathrm{Cl}$ & $\overline{\mathrm{OR}}$ & $p$ value & $\mathrm{Cl}$ & OR & $p$ value & $\mathrm{Cl}$ \\
\hline \multicolumn{10}{|l|}{ Vitamin D Status } \\
\hline No Deficient Diagnosis & 1 & & & 1 & & & 1 & & \\
\hline Deficient Diagnosis & 5.84 & $<0.001$ & $5.41-6.33$ & 5.38 & $<0.001$ & $4.95-5.88$ & 1.22 & $<0.001$ & $1.11-1.33$ \\
\hline \multicolumn{10}{|l|}{ Gender } \\
\hline Male & & & & 1 & & & 1 & & \\
\hline Female & & & & 2.34 & $<0.001$ & $2.25-2.42$ & 1.35 & $<0.001$ & $1.29-1.40$ \\
\hline \multicolumn{10}{|l|}{ Age Group, Years } \\
\hline $18-24$ & & & & 2.22 & $<0.001$ & $2.05-2.40$ & 1.13 & 0.006 & $1.04-1.24$ \\
\hline $25-34$ & & & & 1.55 & $<0.001$ & $1.45-1.67$ & 1.15 & $<0.001$ & $1.07-1.25$ \\
\hline $35-44$ & & & & 1.17 & $<0.001$ & $1.09-1.23$ & 1.14 & 0.001 & $1.05-1.23$ \\
\hline $45-64$ & & & & 1 & & & 1 & & \\
\hline \multicolumn{10}{|l|}{ Service Type } \\
\hline Active Guard & & & & 1 & & & 1 & & \\
\hline Active Duty & & & & 3.29 & $<0.001$ & $3.11-3.48$ & 1.24 & $<0.001$ & $1.16-1.32$ \\
\hline \multicolumn{10}{|l|}{ Career Type } \\
\hline Officer & & & & 1 & & & 1 & & \\
\hline Enlisted & & & & 2.62 & $<0.001$ & $2.46-2.79$ & 1.66 & $<0.001$ & $1.56-1.78$ \\
\hline \multicolumn{10}{|l|}{ Career Progression } \\
\hline Senior Rank & & & & 1 & & & 1 & & \\
\hline Junior Rank & & & & 1.05 & 0.019 & $1.01-1.10$ & 1.02 & 0.443 & $0.97-1.06$ \\
\hline \multicolumn{10}{|l|}{ MTF Location } \\
\hline Watertown, NY & & & & 1 & $<0.001$ & & 1 & $<0.001$ & \\
\hline Fairbanks, AK & & & & 1.34 & $<0.001$ & $1.19-1.49$ & 1.92 & $<0.001$ & $1.71-2.17$ \\
\hline Killeen, TX & & & & 2.41 & $<0.001$ & $2.25-2.58$ & 2.94 & $<0.001$ & $2.73-3.16$ \\
\hline Tacoma, WA & & & & 1.19 & $<0.001$ & $1.10-1.28$ & 1.53 & $<0.001$ & $1.41-1.66$ \\
\hline El Paso, TX & & & & 1.35 & $<0.001$ & $1.25-1.45$ & 1.99 & $<0.001$ & $1.85-2.16$ \\
\hline Fayetteville, NC & & & & 1.15 & $<0.001$ & $1.07-1.24$ & 1.54 & $<0.001$ & $1.43-1.67$ \\
\hline
\end{tabular}

Abbreviations: $O R$ odds ratio, $\mathrm{Cl}$ confidence interval

aincludes only vitamin $D$ diagnosis

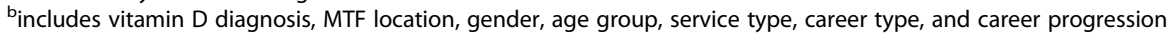

includes vitamin D diagnosis, MTF location, gender, age group, service type, career type, career progression, and associated encounters as a continuous variable

that a much larger number of personnel included in this study may have been vitamin $D$ deficient but never received testing or diagnosis. Previous studies that report a higher prevalence of vitamin D deficiency in military populations describe research methods that include vitamin D testing or access to vitamin $\mathrm{D}$ status for the entire sample $[15,16]$. Additionally, a portion of the low prevalence may be attributed to variation in testing and diagnostic methods. In this sample, vitamin D deficient diagnoses were obtained from several different MTFs which prevented the ability to control for variation in provider or facility policies. Although testing for vitamin D levels has become common practice in most healthcare facilities, potential variability in how providers identify patients as vitamin $\mathrm{D}$ deficient may lead to underreporting and misdiagnoses [30].

For depression diagnoses, 16,688 total records in the sample were found to contain one or more diagnostic code for depression. Although low, the overall prevalence of depression $(4.37 \%)$ is comparable to that of previous studies which include military personnel. Diagnoses of depression were highest among females, the enlisted group, and the 18-24 year old age group. These results are not surprising as other studies have reported a higher prevalence of depression among females and in younger age demographics $[3,31]$. Other studies estimate that the 


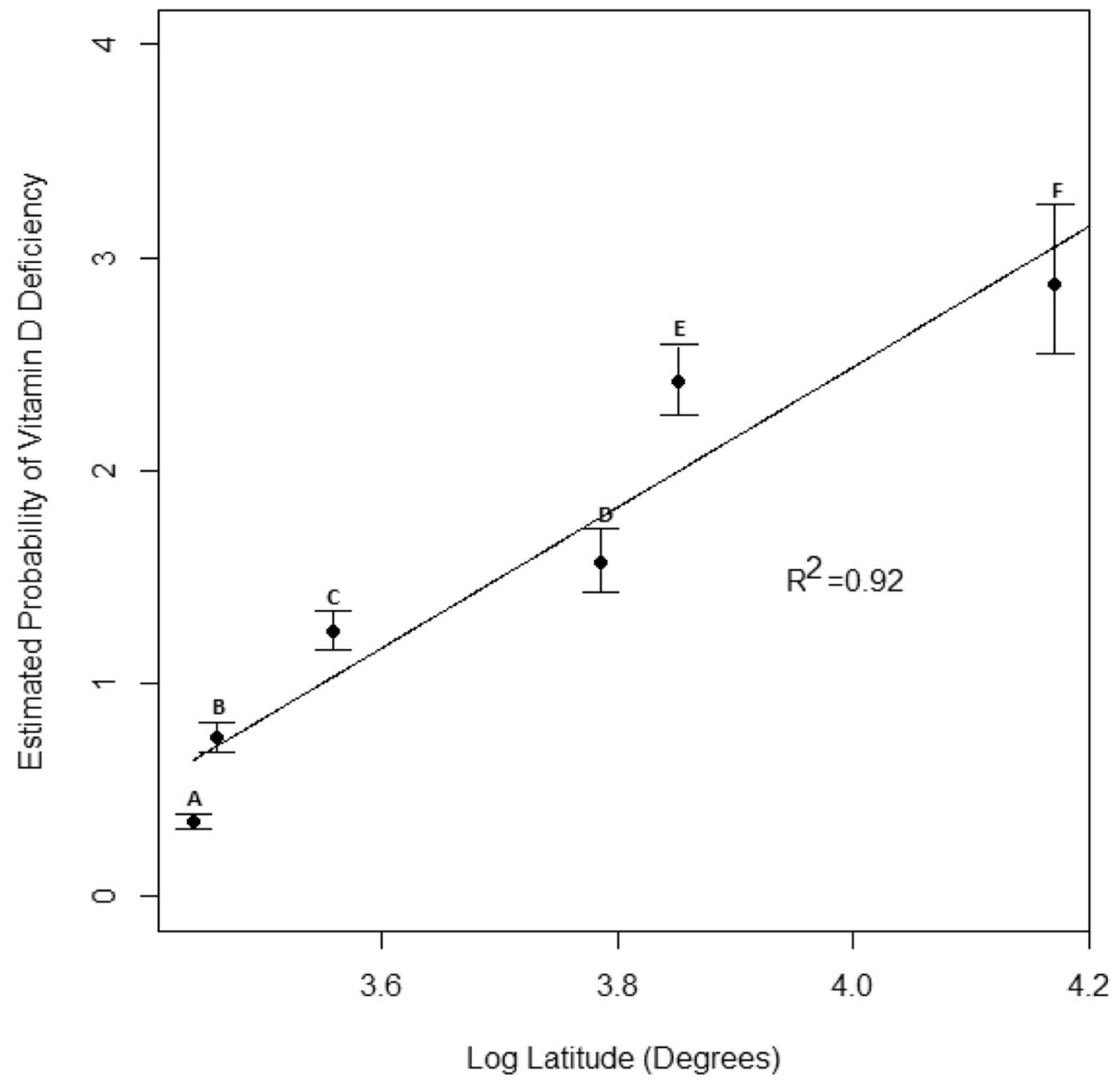

Fig. 2 The relationship between vitamin D deficiency in active duty service members at six different MTF locations by degree of latitude

prevalence of depression in the U.S. military population varies widely (from 2 to $37.4 \%$ ) [3]. Variability in the prevalence for depression in military samples may be related to differences in population samples, combat exposure, reporting methods, or the type of screening tool used by providers to diagnose for depression [5]. In previous evaluations of intervention programs for posttraumatic stress disorders (PTSD) and depression, it has been noted that missed diagnoses of depression may occur if providers complete the clinical assessment or referral process incorrectly [32, 33]. Additionally, as with the methods for determining vitamin $\mathrm{D}$ status, the nature of this study design prevented insight as to how many personnel in the sample were screened for depression. While questionnaire-based screening for depression occurs at set intervals in the military, it has been reported that in addition to errors in administration, a low prevalence of depression may also be related to the hesitance of military personnel to endorse symptoms during physical clinical assessments [32, 33].

The unadjusted relationship between vitamin D deficiency diagnoses and depression diagnoses, reported in this study, was much stronger $(\mathrm{OR}=5.84)$ than the unadjusted relationship reported by similarly designed populationbased studies $[19,34]$. The relationship remained significant even after controlling for covariates known to be associated with depression such as location, gender, age, career type, career progression, and number of medical encounters $(\mathrm{OR}=5.38)$. Personnel in the study sample without a diagnosis of vitamin $\mathrm{D}$ deficiency, potentially related to inconsistent screening of vitamin D status in the military, may indicate that there are actually a higher number of personnel with a depression diagnoses that are also vitamin D deficient. If this is the case, then the relationship between vitamin $\mathrm{D}$ deficiency and depression may be even stronger than reported in the present study. While limited by the observational nature of this study, the strong relationship between vitamin D deficiency and depression is of concern, as several other studies have demonstrated a causal relationship between vitamin $\mathrm{D}$ deficiency and depression. Both Vieth et al. [35] and Jorde et al. [36] reported that vitamin D supplementation improved participants' well-being scores and depression scores, respectively. These findings may 
be of relevance to the military population as vitamin $\mathrm{D}$ deficiency is relatively easy to test for and may lead to earlier treatment or prevention of mental health conditions.

Though this study initially demonstrated a strong relationship between vitamin $\mathrm{D}$ and depression, the relationship was much weaker in the analysis which included the number of patient encounters as a covariate. After controlling for the number of encounters and demographic covariates, the adjusted relationship between vitamin $\mathrm{D}$ and depression $(\mathrm{OR}=1.22)$ is very similar to the adjusted result $(\mathrm{OR}=1.85)$ reported by Ganji et al. [34] As the design of this study cannot determine causality, it is unclear if individuals with depression have greater health care encounters as a result of diagnosis or if individuals with greater numbers of medical encounters are more likely to be diagnosed with depression. Beghofer et al. [37] also concluded that it was not possible to determine whether a diagnosis of depression is a risk factor for greater health care utilization, or instead an outcome of increased morbidity.

Despite a low overall prevalence of vitamin D deficiency, this study demonstrated a significant linear relationship $\left(r^{2}=0.92\right)$ between latitude and vitamin D deficiency percentages. This is particularly concerning as exposure to UV light is a critical source of vitamin D. Previous research also supports that differences in geographic location, even a one-degree difference in latitude, can have a significant impact on vitamin D status [38]. These results are meaningful, given that U.S. military personnel may be stationed at installations in geographic areas with inadequate UV exposure for several years. However, the analysis of these results is limited by the fact that this study could not control for other known covariates of vitamin D status such as skin tone, season of the year, weather, sunscreen use, body mass index (BMI), and vitamin D intake. Nevertheless, these findings further advocate for standardized vitamin D testing, especially for service members stationed at northern latitudes, as vitamin $\mathrm{D}$ deficiency may be related to depression.

Contrary to the relationship between vitamin D deficiency and latitude, this study did not find a significant relationship between depression and latitude. Rates of depression were highest for the MTF located in Killeen, TX and lowest for the MTF located in Watertown, NY. This may suggest that additional factors such as work-related stress, combat exposure, military occupational specialty, and the number of deployments, also affect the relationship, regardless of geographic location [39]. Additionally, other demographic factors, that are known to correlate with depression may be more strongly associated with depression than geographic location and were not controlled for in this study.

\section{Conclusions}

Vitamin D deficiency is a worldwide problem with a growing number of known health implications. This study demonstrated that active duty service members with a diagnosis of vitamin $\mathrm{D}$ deficiency were much more likely to have a diagnosis of depression. Although further studies are needed to support this relationship, this may highlight the usefulness of vitamin D testing as an additional screening method for depression. Vitamin D testing, in conjunction with current screening tools, may be a better approach to circumvent service members who are reluctant to seek care for mental health conditions. This may especially be true for service members who are stationed at installation located in northern latitudes who present a higher risk for depression. Implementing standardized policies for vitamin D testing and diagnosing could be instrumental in increasing the likelihood that service members are diagnosed as vitamin $\mathrm{D}$ deficient and are identified for mental health interventions sooner rather than later.

\section{Acknowledgements}

Not applicable.

\section{Authors' contributions}

NB formulated the study concept and design. JK acquired data used in the study and assisted in the interpretation of this data. KS and DB interpreted data, drafted the manuscript, and completed the data analysis and interpretation. $A B$ helped advise the direction of the manuscript and made substantial revisions. Each author has read and approved the final manuscript prior to submission.

\section{Funding}

The authors have no funding sources to declare.

\section{Availability of data and materials}

The datasets generated and analyzed during the current study are available from the corresponding author upon reasonable request.

Ethics approval and consent to participate

This human subject research was deemed exempt as it involved the study of existing data and information was recorded in such a manner that subjects could not be identified. This study was deemed exempt by the Human Protections Administrator at the Army Medical Department Center and School and was approved by the Institutional Review Board at Walter Reed National Military Medical Center.

Consent for publication

Not Applicable

\section{Competing interests}

The authors declare that they have no competing interests.

\section{Author details}

${ }^{1}$ U.S. Baylor Military Graduate Program in Nutrition, 3630 Stanley Road, San Antonio, TX 78234, USA. ${ }^{2}$ Nutrition Services Department, Walter Reed National Military Medical Center, 8901 Wisconsin Avenue, Bethesda, MD 20889, USA. ${ }^{3}$ Department of Research Programs, Walter Reed National Military Medical Center, 8901 Wisconsin Avenue, Bethesda, MD 20889, USA. ${ }^{4}$ Health Readiness Center of Excellence, Capability Development Integration Directorate, 3630 Stanley Road, San Antonio, TX 78234, USA. ${ }^{5}$ Military Nutrition Division, U.S. Army Research Institute of Environmental Medicine, 10 General Greene Ave, Natick, MA 01760, USA. 
Received: 1 May 2019 Accepted: 27 August 2019

Published online: 10 September 2019

\section{References}

1. Depression. NIMH RSS. http://www.nimh.nih.gov/health/topics/depression/ index.shtml\#part_145400. Accessed 27 Jan 2016.

2. Stein MB, Ursano RJ. Suicide among United States military personnel: determining the root causes: suicide among US military personnel. Depress Anxiety. 2013;30:896-7.

3. Gadermann AM, Engel CC, Naifeh JA, et al. Prevalence of DSM-IV major depression among U.S. military personnel: meta-analysis and simulation. Mil Med. 2012;177:47-59.

4. Institute of Medicine. Preventing psychological disorders in service members and their families: an assessment of programs. Mil Med. 2014;179: $1173-5$.

5. Warner $\mathrm{CH}$, Appenzeller GN, Grieger $\mathrm{T}$, et al. Importance of anonymity to encourage honest reporting in mental health screening after combat deployment. Arch Gen Psychiatry. 2011;68:1065-71.

6. Held P, Owens GP. Stigmas and attitudes toward seeking mental health treatment in a sample of veterans and active duty service members. Traumatology. 2013;19:136-43.

7. Eyles DW, Burne THJ, McGrath JJ. Vitamin D, effects on brain development, adult brain function and the links between low levels of vitamin $D$ and neuropsychiatric disease. Front Neuroendocrinol. 2013;34:47-64.

8. Patrick RP, Ames BN. Vitamin D hormone regulates serotonin synthesis. Part 1: relevance for autism. FASEB J. 2014:28:2398-413.

9. Anglin RES, Samaan Z, Walter SD, McDonald SD. Vitamin D deficiency and depression in adults: systematic review and meta-analysis. Br J Psychiatry J Ment Sci. 2013;202:100

10. Holick MF. Vitamin D deficiency. N Engl J Med. 2007;357:266-81

11. Forrest KY, Stuhldreher WL. Prevalence and correlates of vitamin D deficiency in US adults. Nutr Res. 2011;31:48-54.

12. Tangpricha V, Pearce EN, Chen TC, Holick MF. Vitamin D insufficiency among free-living healthy young adults. Am J Med. 2002;112(8):659-62.

13. Holick MF, Binkley NC, Bischoff-Ferrari HA, et al. Evaluation, treatment, and prevention of vitamin D deficiency: an Endocrine Society clinical practice guideline. J Clin Endocrinol Metab. 2011;96:1911-30.

14. Göring H, Koshuchowa S. Vitamin D deficiency in Europeans today and in Viking settlers of Greenland. Biochem Mosc. 2016;81:1492-7.

15. Umhau JC, George DT, Heaney RP, et al. Low vitamin D status and suicide: a case-control study of active duty military service members. PLoS One. 2013; 8:e51543.

16. Funderburk LK, Daigle K, Arsenault JE. Vitamin D status among overweight and obese soldiers. Mil Med. 2015:180:237-40.

17. Hoogendijk WJG, Lips P, Dik MG, Deeg DJH, Beekman ATF, Penninx BW. Depression is associated with decreased 25 -Hydroxyvitamin D and increased parathyroid hormone levels in older adults. Arch Gen Psychiatry. 2008;65:508-12.

18. Stewart R, Hirani V. Relationship between vitamin D levels and depressive symptoms in older residents from a national survey population. Psychosom Med. 2010;72:608-12.

19. Lapid MI, Cha SS, Takahashi PY. Vitamin D and depression in geriatric primary care patients. Clin Interv Aging. 2013;8:509-14.

20. Knippenberg S, Bol Y, Damoiseaux J, Hupperts R, Smolders J. Vitamin D status in patients with MS is negatively correlated with depression, but not with fatigue. Acta Neurol Scand. 2011;124:171-5.

21. Pan A, Lu L, Franco OH, Yu Z, Li H, Lin X. Association between depressive symptoms and 25-hydroxyvitamin D in middle-aged and elderly Chinese. J Affect Disord. 2009;118:240-3.

22. Nanri A, Mizoue T, Matsushita Y, et al. Association between serum 25hydroxyvitamin $\mathrm{D}$ and depressive symptoms in Japanese: analysis by survey season. Eur J Clin Nutr. 2009;63:1444-7.

23. U.S. Army Public Health Center. Health of the Force Report. Aberdeen Proving Ground: MD; 2016

24. Barlas F, Higgins W, Pflieger J, Dieckler K. 2011 Department of Defense Health Related Behaviors Survey of Active Duty Military Personnel. ICF International. 2013.

25. Guide For DoD Researchers on Using MHS Data. Office of the Assistant Secretary of Defense for Health Affairs; 2017. p. 1-3. Available at: https:// health.mil/Reference-Center/Publications/2012/10/10/Guide-for-DoDResearchers-on-Using-MHS-Data. Accessed 27 June 2017
26. Centers for Medicare \& Medicaid Services (U.S.), National Center for Health Statistics (U.S.), Centers for Disease Control and Prevention (U.S.). ICD-9-CM: international classification of diseases, ninth revision, clinical modification. 6th ed. Washington, D.C: U.S. Dept. of Health and Human Services, Centers for Disease Control and Prevention, Centers for Medicare and Medicaid Services; 2002

27. American Psychiatric Association. DSM-5 Task Force, American Psychiatric Association. In: Diagnostic and Statistical Manual of Mental Disorders: DSM5. 5th ed: Arlington, American Psychiatric Association; 2013.

28. Chuang C, Yang T, Muo C, Su H, Sung F, Kao C. Hyperlipidemia, statin use and the risk of developing depression: a nationwide retrospective cohort study. Gen Hosp Psychiatry. 2014;36:497-501.

29. Gossop M, Tsai C, Liao Y, et al. Association between depression and enterovirus infection: a nationwide population-based cohort study. Medicine. 2017;9:e5983.

30. Epling J, Mader E, Roseamelia C, Morley C. Emerging practice concerning vitamin D in primary care. Qual Health Res. 2014;25(7):1005-12. https://doi. org/10.1177/1049732314554100.

31. Elbogen EB, Wagner HR, Johnson SC, et al. Are Iraq and Afghanistan veterans using mental health services? New data from a National RandomSample Survey. Psychiatr Serv. 2013;64:134-41.

32. DCOE (Defense Centers of Excellence for Psychological Health \& Traumatic Brain Injury). RESPECT-Mil: Re-engineering Systems of Primary Care Treatment in the Military. 2012.

33. Wong EC, Jaycox LH, Ayer $\mathrm{L}$, et al. Evaluating the implementation of the reengineering Systems of Primary Care Treatment in the military (RESPECTmil). Rand Health Q. 2015;5(2):13

34. Ganji V, Milone C, Cody MM, McCarty F, Wang YT. Serum vitamin D concentrations are related to depression in young adult US population: the third National Health and nutrition examination survey. Int Arch Med. 2010;3:29.

35. Vieth R, Kimball S, Hu A, Walfish PG. Randomized comparison of the effects of the vitamin D3 adequate intake versus $100 \mathrm{mcg}$ (4000 IU) per day on biochemical responses and the wellbeing of patients. Nutr J. 2004:3:8-8.

36. Jorde R, Sneve M, Figenschau Y, Svartberg J, Waterloo K. Effects of vitamin D supplementation on symptoms of depression in overweight and obese subjects: randomized double blind trial. J Intern Med. 2008;264:599-609.

37. Berghöfer A, Roll S, Bauer M, Willich SN, Pfennig A. Screening for depression and high utilization of health care resources among patients in primary care. Community Ment Health J. 2014;50:753-8.

38. Yeum K, Song BC, Joo N. Impact of geographic location on vitamin D status and bone mineral density. Int J Environ Res Public Health. 2016;13:184.

39. Pflanz S. Work stress in the military: prevalence, causes, and relationship to emotional health. Mil Med. 2002;167(11):877-82.

\section{Publisher's Note}

Springer Nature remains neutral with regard to jurisdictional claims in published maps and institutional affiliations.

Ready to submit your research? Choose BMC and benefit from:

- fast, convenient online submission

- thorough peer review by experienced researchers in your field

- rapid publication on acceptance

- support for research data, including large and complex data types

- gold Open Access which fosters wider collaboration and increased citations

- maximum visibility for your research: over $100 \mathrm{M}$ website views per year

At $\mathrm{BMC}$, research is always in progress.

Learn more biomedcentral.com/submission 